\title{
Research on the Training Mode of Excellent Agriculture and Forestry Talents in Local Colleges and Universities
}

\author{
Zhao Xianglian \\ Center for Teaching and Learning Development \\ Jilin Agricultural University \\ Changchun, China
}

\author{
Sun Bin \\ Graduate School of \\ Jilin Agricultural University \\ Changchun, China
}

\author{
Zhou Jianzhong \\ Center for Teaching and Learning Development \\ Jilin Agricultural University \\ Changchun, China
}

\begin{abstract}
In 2012 the ministry of education launched outstanding talents of agriculture and forestry education training plan. Vigorously Promote the Combination of Production, Teaching and Research, Agricultural Science and Education to Cultivate High - quality Talents of Agriculture and Forestry. But at present, the domestic research of cultivating higher agricultural colleges are also at the exploration stage, only a complete training program and university-enterprise cooperation training modes, curriculum system, teaching staff construction, practice ability promotion system has not yet formed, lack of forming theory, research and practice remains to be seen. Outstanding talent training mode of agriculture and forestry, the research is of higher education effective response to national agricultural demand. Jilin agricultural university, make full use of the advantages of agriculture, forestry and discipline, promote the professional teaching and fusion of foreign language teaching, has been committed to internationalization of talents cultivation, and gradually formed the elite education and popularization of quality education with the combination of outstanding talent cultivation system. At the same time also greatly enrich the theory of "outstanding talents" cultivation, opened up the higher education and social docking, joint training and new research perspective of cooperation. Through the implementation of the program to promote educational reform, significantly increasing the innovative ability of students, enhance the ability of colleges and universities to serve the local economic construction.
\end{abstract}

Keywords-Agriculture and Forestry outstanding talent, training mode

Research 2012 "Excellence Agriculture and Forestry Talents Training Mode" in the subject in school research project, Jilin Agricultural University as the basis, to serve the society and economy of Jilin Province "three rural" development as the purpose, to respond to major national strategic needs for the ultimate goal, bringing together universities, local governments and enterprises tripartite strength, excellence agriculture and forestry personnel training mode mechanism of in-depth study and exploration, in 2012 design of Jilin Agricultural University, excellent talent training plan framework map, the development of "Training Excellence program" curriculum program, the issuance of " Jilin Agricultural University "excellent talent training plan" the opinions ", the same year in 2012 plant protection, veterinary medicine, food science and engineering in the first three professional implementation of the plan. Team members, the supervision of the teams to the teacher of grade 2012 plant protection professional tracking investigation, and formed a "Jilin Agricultural University" outstanding talent cultivation of agriculture and forestry plan implementation effect evaluation report ".From 2013 to 2016, the model in the process of implementing improved step by step, after many years of practice has formed suitable for local agricultural colleges of outstanding talent training mode of agriculture and forestry.

\section{CLEAR TARGETING LOCAL AGRICULTURAL UNIVERSITIES OF EXCELLENCE IN AGRICULTURE AND FORESTRY PERSONNEL TRAINING AND BASIC REQUIREMENTS}

Through years of exploration, the cultivation of this achievement clearly positioning outstanding talents: a comprehensive communicative competence of students, based on practice, innovation, employment, entrepreneurship and self-learning ability "Five Abilities", highlighting innovative ability of students training, training base deep academic proficiency, vision development, superb quality, innovative spirit and practical ability to adapt to economic and social development needs of top creative talents and have career aspirations of devotion to country agriculture, forestry, agroforestry production to solve practical problems of high levels Applied Talents.

To achieve this purpose the culture, summed up the results of this basic requirement of Training Excellence :

\section{A. Broaden their international exposure and global}

awareness of students has an important role.

Through the introduction of advanced teaching philosophy, curriculum and the use of international knowledge, Professor frontier and international professional knowledge, can contribute to improve the level of students' foreign language learning and teaching development without lowering requirements while broadening international students vision 
and global awareness of students, improve students' ability to compete in the future in the development of modern agriculture.

\section{B. Implementation of research teaching is an important way to cultivate students' self-learning ability and creative ability.}

Research Teaching help improve students' self-learning ability and creative spirit. The results of the group of University Talents and social needs, and actively explore innovative ability based on undergraduate research study target mode, the initial formation of the theoretical system of research and teaching research study, and applied in practice in the Training Excellence, the formation of a research study curriculum, promote teachers update teaching concept and mode.

\section{TO FULLY EMBODY THE TARGET OF TALENT CULTIVATION PUT FORWARD TWO KINDS OF TALENT CULTIVATION MODEL, THREE KINDS OF DEPTH FUSION CONCEPT.}

Training Excellence to carry out "applied" to the main and "academic research" as the two modes culture:

1. "Experimental class" to take the " $3+1$ " training mode. To cultivate students' creative ability and practical application of the first three years were on campus culture, to the fourth year of business, farms campus culture.

2. Excellence class" to implement this Shuoboliandu take " $3+2+3+1$ "training mode. Undergraduate courses three years ago, the fourth year of direct access to the Master's course of study, students in accordance with national policy and practical case $2+1$ master stage of the culture, the culture $\mathrm{PhD} 3+1$ year.

Adhere to the teaching and the depth of integration of foreign language teaching. Strengthen the depth of the provincial agricultural education and overseas education, draw lessons from foreign advanced training concept and course at the university of modules. The introduction of foreign teachers or background of high level professional teachers to study abroad to all the students' native international education and the education of agriculture and forestry. In consolidating student discipline basis, while further strengthening the practical teaching, the full implementation of multi-level classification type of practice teaching reform, to explore practical and innovative ability cultivation practice teaching model as the core, in particular to strengthen the students' international experience.

\section{FORMATION OF OPERATION AND MANAGEMENT MODE}

To form a new training program, to establish excellent talent training frame, etc., and formed a set of unique characteristics, suitable for the excellence of our school's actual forestry school personnel training mode.

1. Form "about two agricultural colleges' top creative talents cultivation" research report. Achievements group members have participated in the training organized by the Ministry of Education, Higher Education grasp the new situation, to learn about new developments in other Universities Course Construction and experience gained into practice in our school of excellence in personnel training.
While actively communicate with agricultural and forestry colleges, 2012 respectively, South China Agricultural University "Ding Ying" Experimental Class and the Northwest Agriculture and Forestry University, "Experimental School of Innovation" at start-up time, professional category, source of students, lessons learned, length of schooling, training type, carried out all aspects of research and lessons learned on the basic case management, training methods. She wrote "about two agricultural colleges' top creative talents cultivation" research report. Lay a foundation for implementation outstanding talent training plan in the next step.

2. The establishment of Jilin Agricultural University "excellent talent training plan" of organization, culture determines the framework in FIG. Widely solicited opinions on the basis of student management and other personnel and training programs further provisions to provide organizational and institutional safeguards established Training Excellence "Jilin Agricultural University" plan "Student Selection and enrollment management approach for the introduction of Excellence (trial) "," Jilin Agricultural University "excellent talent training plan" professional personnel training program revision of guidance "," Jilin Agricultural University "excellent talent training plan" opinions "and so on.

3. Formed a "Jilin Agricultural University" outstanding, forestry and talent training plan implementation effect evaluation report ". Implemented in the 2012-2015 level of plant protection, veterinary medicine, food science and engineering training programs in three professional teaching reforms, "excellence talent training plan" tracking survey summary. Governor of the Steering Group for 2012-2015 grade teacher guide plant protection and other professional follow-up survey report is formed. Binding opinion of the Steering Group recommendations and Dean research, summed up the formation of the "Jilin Agricultural University 'outstanding agricultural and forestry personnel training programs' implementation of the Evaluation Report." In order to further execution excellence program especially for level 2016 more perfect to provide important basis. To promote the school and enterprise, base, or research institutes cooperation mechanism research, attract enterprise deeply involved in talents cultivation process.

\section{PROMOte THE "FOUR INTERNATIONAL" AS THE CORE OF THE LOCAL INTERNATIONAL TEACHING REFORM}

\section{A. Build an international curriculum.}

(1) By revising teaching plans to build a new system of general education of the whole person, carefully build the core general e ducation curriculum and the quality of international education courses in order to strengthen the comprehensive group of students humanities, critical thinking and other aspects of international awareness.

(2) Learn from foreign advanced teaching philosophy courses, the introduction of professional courses internationally renowned universities.Establishment of interdisciplinary courses elective system. 


\section{B. Create international excellent teachers.}

Enrich the teaching experience, keen to associate professor titles and more than teaching reform of teacher quality and excellent as a lecturer with a doctorate.Based on pilot professional schools and colleges in detail about the content and course arrangement, mining high quality teacher resources. Hire experts, face-to-face teaching masters, executives at all levels for the pilot professional courses or seminar. At the same time employ enterprise backbone personnel to school as parttime teachers in order to establish a relatively stable business part-time teachers. Short-term training to outstanding class teachers both at home and abroad. Various comprehensive assessment, and constantly improve the teachers' evaluation mechanism.

\section{Using international teaching methods}

Promote heuristic, inquiry, discussion teaching, practice in small classes mode.Pay attention to the whole process of assessment, construction of all-round, multi-angle evaluation mechanism from the student course exam, ability test, and other aspects of the level of innovative practice and the use of a variety of assessment forms.Setting seminars for freshmen in order to guide the students to adapt to the transition from traditional to impart knowledge mainly to exploration and research-based teaching.Promote common development of undergraduate study and carry out independent research study courses related to system performance evaluation and student assessment.

\section{Explore international teaching management.}

Promoting the "internationalization, humane, standardized, refinement and information," teaching management system, the implementation of tracking programs, develop an international management team.

\section{CONCLUSION}

University talent training model is a comprehensive, dynamic concept, the reform of personnel training model to give full consideration to the law of education and teaching, the actual situation of the school and society, the market demand for talent and many other factors. At the same time, we also need to be verified and summarized in the actual process, deepening the understanding of the university talent training mode, through in-depth and lasting practice, understanding, and then practice, re-understanding of continuous exploration, continuous improvement in development. Only in this way, we cultivate students can truly become to meet the needs of the community of all kinds of useful talents, in order to build a well-off society and socialist modernization building.

\section{REFERENCES}

[1] Zhu Xiulin. Local colleges and universities to usher in new opportunities for development [J]. China's higher education. 2015 (22)

[2] Zhou Zhicheng, Zhou Huali. An analysis of the concept of entrepreneurship education in local undergraduate colleges and universities [J]. China's higher education. 2015 (20)

[3] Liu Aichen, Wang Wei. Research on the cultivation of excellent talents of agriculture and forestry [J]. Heilongjiang animal husbandry and veterinary medicine. 2015 (19)

[4] Cao Liying. The characteristics of European and American university education to the quality education of Chinese Agricultural Colleges and universities and Its Revelation [J]. World agriculture. 2015 (09)

[5] Shi Juhua, Geng Bradley. Excellent forestry plan of cultivating topnotch innovative talents of university laboratory [J]. Path selection (04) 2014.

[6] Liu Zhanzhu, Shang Wei, Yao Dan, Li Yafei. Research on the cultivation of excellent talents of agriculture and forestry across the big class [J]. Higher agricultural education. 2015 (01) 